\title{
Exploring Effects of Different Roles on Using an E-learning Service
}

\author{
H.J. Yang \& L.H. Kuo \\ National Kaohsiung Normal University, Taiwan, R.O.C.
}

\begin{abstract}
The purpose of this study was to explore effects of different roles on learning satisfaction. For better hosting a e-learning service, there is a need to understand user's satisfaction of the learning service. Data was collected from an on-line learning system. Based upon course learning activities, each course was assign to a certain role for the learner. There are six types of learning role from all course. 1) Reporter, 2) Listener, 3) Researcher, 4) Reporting Listener, 5) Reporting Researcher, 6) Report Listen Researcher; One-way ANOVA procedure was applied to exploring whether the role difference affects users satisfaction. According to the significant level less than .05, it was concluded that learning satisfaction of different roles are significant different. On the other word, learning roles affect users' learning satisfaction.
\end{abstract}

\section{Introduction}

\subsection{E-learning Platform}

In this information age, information system provides a flexible communication solution. It also plays an important way for supporting personal learning by establishing well organized educational environment.

E-learning is becoming an increasingly large part of higher education (Anderson, 2014, Duck and Parente, 2014, Kim, 2011). Over 7.1 million college and university students took at least one online course by the end of the fall 2012 semester in the United States (Allen and Seaman, 2014). More than $71 \%$ of US colleges and universities offered online courses in 2012(Allen and Seaman, 2013) and one-third of higher education students took at least one online course in 2012 (Allen and Seaman, 2014).

\subsection{Problem Statement}

The purpose of this study was to explore effects of different roles on learning satisfaction. For better hosting a e-learning service, there is a need to understand user's satisfaction of the learning service.

Data was collected from an on-line learning system. Based upon course learning activities, each course was assign to a certain role for the learner. There are six types of learning role from all course. 1) Reporter, 2) Listener, 3) Researcher, 4) Reporting Listener, 5) Reporting Researcher, 6) Report Listen Researcher

a Corresponding author: admi@nknucc.nknu.edu.tw

\section{E-learning satisfaction}

E-learning has been described as technology-based learning (Ali and Leeds, 2009, Kim, 2011), web-based learning (Bakia et al., 2012), network- and computerbased learning (Angelina et al., 2007), or "instructional environments supported by the Internet" (Bakia et al., 2012). Although each researcher uses different terms to describe the phenomenon of e-learning, the common element in all of the research is that learners need to be familiar with using computer technology and the Internet to take online courses.

E-learning environments in higher education in the United States have been

expanding rapidly (Allen and Seaman, 2014). Online enrollment as a percentage of the total enrollments in U.S. universities was less than $10 \%$ in 2002 , whereas it reached more than $33.5 \%$ in 2012 (Allen and Seaman, 2014). The benefit of e-learning is that distance learners can study anytime anywhere at their own pace without the limitations of time and space, a factor which led to the rapid growth of e-learning. However, e-learning is still confronted with a number challenges, such as student readiness for taking an online course and lower retention rates when compared to the traditional face-to-face course.

\section{Methodology}

\subsection{Data Collection}

For better hosting a e-learning service, there is a need to understand user's satisfaction of the learning service. Data was collected from an on-line learning system. Based upon course learning activities, each course was 
assign to a certain role for the learner. There are six types of learning role from all course. 1) Reporter, 2) Listener, 3) Researcher, 4) Reporting Listener, 5) Reporting Researcher, 6) Report Listen Researcher.

Learning Satisfaction is represented as Likert Scale from 1 to 5 as not satisfied to fully satisfied and 3 is the middle value.

\subsection{One-way ANOVA}

One can use the One-Way ANOVA procedure to test the hypothesis that the means of two or more groups are not significantly different.

One-Way ANOVA also offers:

- Group-level statistics for the dependent variable

- A test of variance equality

- A plot of group means

- Range tests, pairwise multiple comparisons, and contrasts, to describe the nature of the group differences

Descriptive statistics are shown in followings:

$$
\begin{aligned}
& \text { Sample size }=W_{q} \\
& \text { Mean }=\bar{T}_{q} \\
& \text { Standard deviation }=S_{q} \\
& \text { Standard error }=S_{q} / \sqrt{W_{q}}
\end{aligned}
$$

$95 \%$ confidence interval for the mean:

$$
\bar{T}_{q} \pm t_{W_{q}-1} S_{q} / \sqrt{W_{q}}
$$

Where $t_{\mathrm{Wq}-1}$ is the upper $2.5: \%$ critical value for the $t$ distribution with Wq-1 degrees of freedom.

In a ANOVA table, there are three source of variation.

Between (BSS), $\mathrm{df}=\mathrm{k}$ '-1

$$
\sum_{l=1}^{k} T_{l}^{2} / n_{l}-G^{2} / W
$$

Within (WSS), df=W-k'

$$
\sum_{\substack{l=1 \\\left(s_{p}^{2} D \text { for matrix input }\right)}}^{k} S S_{l}
$$

Total $(\mathrm{TSS}), \mathrm{df}=\mathrm{W}-1$
Mean squares are calculated by dividing each sum of squares by its degree of freedom. The $\mathrm{F}$ ratio for testing equality of group means is

$$
F=\frac{\text { Mean Square Between }}{\text { Mean Square Within }}=\frac{B S S M}{W S S M}
$$

The significance level is obtained from the $F$ distribution with numerator and denominator degrees of freedom.

Establishment of homogenous subsets could be defined by following procedure. If the sample sized in all groups are equal, or the harmonic mean for all groups has been selected, or the multiple comparison procedure is SNK or DUNCAN, homogeneous subsets are established as follows:

The means are sorted into ascending order from

$$
\bar{T}_{(1)} \text { to } \bar{T}_{\left(k^{\prime}\right)}
$$

Values of $i$ and q such that

$$
\left|\bar{T}_{(q)}-\bar{T}_{(i)}\right| \leq R_{q-i+1} M_{q, i}(*)
$$

Are systematically searched for and

$$
\left\{\bar{T}_{(i)}, \ldots, \bar{T}_{(q)}\right\}
$$

Is considered a homogeneous subset. The search procedure is as follows:

At each step $t$, the value of $i$ is incremented by 1 (the starting value is 1 ), and $\mathrm{q}=\mathrm{k}$ '. The value of $\mathrm{q}$ is then decremented by one until $(*)$ is true. Call this value qt. If $\mathrm{qt}>\mathrm{qt}-1$ and $(*)$ is true,

$$
\left\{\bar{T}_{(i)}, \ldots, \bar{T}_{q_{t}}\right\}
$$

is considered homogeneous. Otherwise $\mathrm{I}$ is incremented and the next step is done. The procedure terminates when $\mathrm{i}=\mathrm{k}$ or $\mathrm{qt}=\mathrm{k}$.

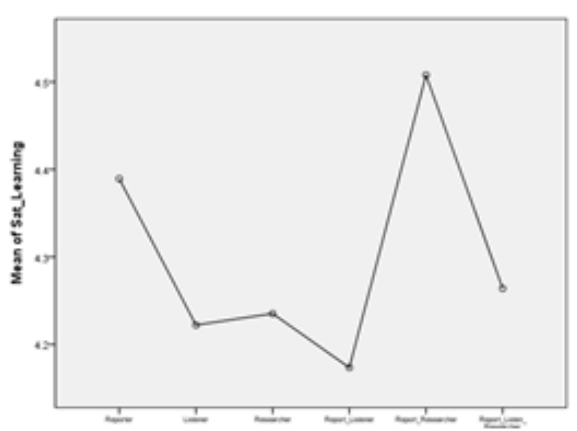

Figure 1. Satisfaction Means plots by each role 


\section{Findings}

In this session, the findings would be reported in descriptive statistics, and One-way ANOVA.

\subsection{Descriptive Statistics}

In Table 1., the descriptive statistics of role were listed. The overall subjects are 837 with $13.5 \%$ reporter, $14 \%$ listener, 20.3\% researcher, 14.5 report listener, 22.8 report researcher, and 14.9 report listen researcher.

Table 1. frequency and percent of Roles

\begin{tabular}{|c|c|c|c|c|}
\hline \multicolumn{5}{|l|}{ Roles } \\
\hline & & & Valid & Cumulative \\
\hline & \multicolumn{4}{|c|}{ FrequencyPercentPercentPercent } \\
\hline ValidReporter & 113 & 13.5 & 13.5 & 13.5 \\
\hline Listener & 117 & 14.0 & 14.0 & 27.5 \\
\hline Researcher & 170 & 20.3 & 20.3 & 47.8 \\
\hline Report Listener & 121 & 14.5 & 14.5 & 62.2 \\
\hline Report Researcher & 191 & 22.8 & 22.8 & 85.1 \\
\hline \multicolumn{2}{|c|}{ Report_Listen_Researcher125 } & 14.9 & 14.9 & 100.0 \\
\hline Total & 837 & 100.0 & 100.0 & \\
\hline
\end{tabular}

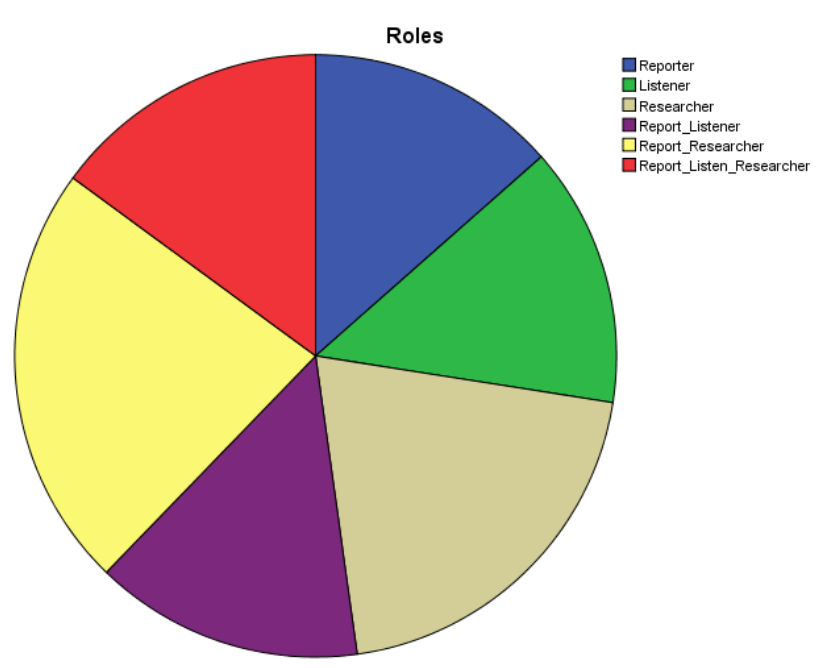

Figure 2. Learning Role distribution

Table 2. Leaning Satisfaction by Roles

\begin{tabular}{|c|c|c|c|c|c|c|c|c|}
\hline & \multirow[b]{2}{*}{$N$} & \multirow[b]{2}{*}{ Mean } & \multicolumn{4}{|c|}{$\begin{array}{l}95 \% \text { Con } \\
\text { Mean } \\
\end{array}$} & \multirow[b]{2}{*}{ Minimum } & \multirow[b]{2}{*}{ Maximum } \\
\hline & & & Std. Deviation Std. & d. Error & Lower Bound & Upper Bound & & \\
\hline Repoter & 113 & 4.39 & .647 & .061 & 4.27 & 4.51 & 2 & 5 \\
\hline Listener & 117 & 4.22 & .696 & .064 & 4.09 & 4.35 & 1 & 5 \\
\hline Researcher & 170 & 4.24 & .655 & .050 & 4.14 & 4.33 & 2 & 5 \\
\hline Report_Listener & 121 & 4.17 & .715 & .065 & 4.04 & 4.30 & 1 & 5 \\
\hline Report_Researcher & 191 & 4.51 & .680 & .049 & 4.41 & 4.60 & 1 & 5 \\
\hline Report_Listen_Researcher & 125 & 4.26 & .824 & .074 & 4.12 & 4.41 & 2 & 5 \\
\hline Total & 837 & 4.31 & .710 & .025 & 4.26 & 4.36 & 1 & 5 \\
\hline
\end{tabular}

Satisfaction is represented as Likert Scale from 1 to 5 as not satisfied to fully satisfied and 3 is the middle value. The learning satisfaction mean for the role of Report Researcher is the highest, 4.51. The standard deviation is . 68 .

\subsection{One-Sample T-Test \& One-way ANOVA}

For exploring overall satisfaction, one-sample T-Test was applied to compare the mean with middle value, 3 , of the Likert Scale. In Table 3, the significance value less than .05 . The value of satisfaction is significantly higher thane middle value 3 .
Table 3. One-sample T-Test of Satisfaction

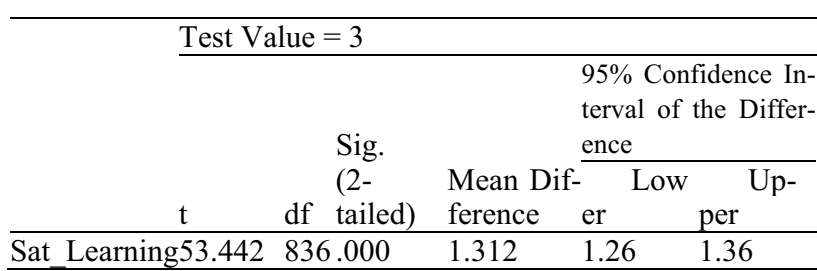

In Table 4, the significant level is less than .05. The test result supports that there exists satisfaction difference among role groups. 
Table 4. ANOVA table of learning satisfaction

\begin{tabular}{|c|c|c|c|c|c|}
\hline & $\begin{array}{l}\text { Sum of } \\
\text { Squares }\end{array}$ & $\mathrm{df}$ & Mean Square & $\mathrm{F}$ & Sig. \\
\hline $\begin{array}{l}\text { Between } \\
\text { Groups }\end{array}$ & 12.554 & 5 & 2.511 & 5.101 & .000 \\
\hline Within Groups & 409.059 & 831 & .492 & & \\
\hline Total & 421.613 & 836 & & & \\
\hline
\end{tabular}

In Teable 6., Duncan test suggested three subsets. Both Reporter and Report Researcher roles is the highest satisfaction set.
Table 5. Homogeneous Subsets by Duncan test

\begin{tabular}{lllll}
\hline \multicolumn{1}{c}{ Duncan, } & \multicolumn{3}{l}{ Subset for alpha $=0.05$} \\
\cline { 2 - 4 } Roles & $\mathrm{N}$ & 1 & 2 & 3 \\
\hline Report_Listener & 121 & 4.17 & & \\
\hline Listener & 117 & 4.22 & 4.22 & \\
\hline Researcher & 170 & 4.24 & 4.24 & \\
\hline Report_Listen_Researcher 125 & 4.26 & 4.26 & \\
\hline Reporter & 113 & & 4.39 & 4.39 \\
\hline Report_Researcher & 191 & & & 4.51 \\
\hline Sig. & & .343 & .075 & .167 \\
\hline
\end{tabular}

Table 6. Post Hoc Tests using Scheffe for multiple comparisons

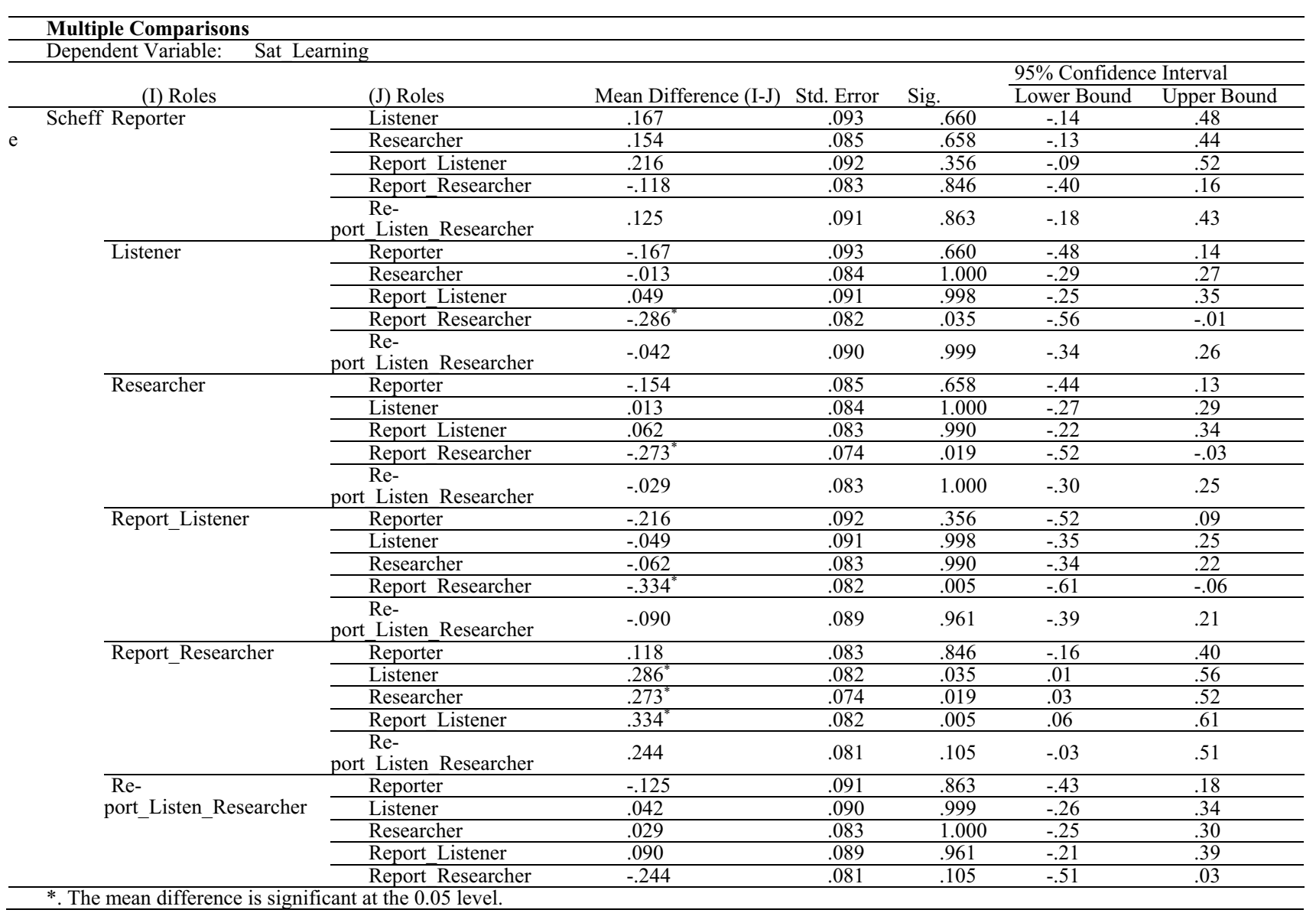

*. The mean difference is significant at the 0.05 level.

In Table 6, those comparisons with significant level less than .05 are:

- Listener to Report Researcher at .035

- Researcher to Report Researcher at .019

- Report Listener to Report Researcher at .005

\section{Conclusions}

The purpose of this study was to explore effects of different roles on learning satisfaction. For better hosting a e-learning service, there is a need to understand user's satisfaction of the learning service. Data was collected from an on-line learning system. Based upon course learning activities, each course was assign to a certain role for the learner.

There are six types of learning role from all course. 1) Reporter, 2) Listener, 3) Researcher, 4) Reporting Listener, 5) Reporting Researcher, 6) Report Listen Researcher; One-way ANOVA procedure was applied to exploring whether the role difference affects users satisfaction. According to the significant level less than .05 , it was concluded that learning satisfaction of 
different roles are significant different. On the other word, learning roles affect users' learning satisfaction.

\section{References}

1. ALI, R. \& LEEDS, E. 2009. The Impact of Face-toFace Orientation on Online Retention: A Pilot Study. Online Journal of Distance Learning Administration, 12.

2. ALLEN, I. E. \& SEAMAN, J. 2013. Changing Course: Ten Years of Tracking Online

3. Education in the United States [Online]. Babson Survey Research Group and Quahog Research Group, LLC.

Available: http://www.onlinelearningsurvey.com/reports/changi ngcourse.pdf [Accessed June 10 2015].

4. ALLEN, I. E. \& SEAMAN, J. 2014. Grade Change: Tracking Online Education in the United States [Online]. Babson Survey Research Group and Quahog Research Group, LLC. Available: http://www.onlinelearningsurvey.com/reports/gradec hange.pdf [Accessed June 10 2015].

5. ANDERSON, P. K. 2014. University education as relational: The challenge of online studies. Contemporary PNG Studies: DWU Research Journal, $19,14$.
6. ANGELINA, L. M., WILLIAMS, F. K. \& NATVIG, D. 2007. Strategies to Engage Online Students and Reduce Attrition. Journal of educators online, 4, 12.

7. BAKIA, M., SHEAR, L., TOYAMA, Y. \& LASSETER, A. 2012. Understanding the Implications of Online Learning for Educational Productivity [Online]. Washington, DC: U.S. Department of Education, Office of Educational Technology. Available: http://www.sri.com/sites/default/files/publications/im plications-online-learning.pdf [Accessed June 10 2015].

8. BERNARD, R. M., BRAUER, A., ABRAMI, P. C. \& SURKES, M. 2004. The development of a questionnaire for predicting online learning achievement. Distance Education, 25, 17.

9. DUCK, J. M. \& PARENTE, D. H. 2014. How Do We Get To Tomorrow? The Path to Online Learning. Developments in Business Simulation and Experiential Learning, 35, 2.

10. KIM, J. 2011. Developing an instrument to measure social presence in distance higher education. British Journal of Educational Technology, 42, 15.

11. LEE, Y. \& CHOI, J. 2013. A structural equation model of predictors of online learning retention. The Internet and Higher Education, 16, 7. 